\title{
The 63rd IFLA conference
}

\section{circuit}

\author{
By Hannelore B. Rader
}

\section{A report from Copenhagen}

$\mathbf{M}$ ore than 2,900 participants from 141 countries met in the beautiful Bela Conference Center in Copenhagen, Denmark during the 63rd Conference of the International Federation of Library Associations (IFLA). Among the attendees were 141 delegates from 86 developing countries sponsored through Danida grants (the Danish government's donor agency). It was the first time that these librarians were able to attend IFLA. One hundred seventy conference papers and more than 80 sessions and discussions centered on the theme "Libraries and Information for Human Development." The U.S. delegation numbered 250 and was well represented in the various meetings and discussions. Many of the sessions were simultaneously translated into IFLA's five official languages: English, French, German, Russian, and Spanish. For the first time an Internet bar featuring 20 workstations and printer facilities was available throughout the conference. For several years now, IFLA homepage (http: /www/nlc-bnc.ca/ifla/) has featured important information about IFLA and the conferences, including full-text papers before and after the conference.

\section{New officers, new committees}

During this conference Robert Wedgeworth finished his six-year term as president of IFLA, and delegates recognized him for his many international contributions. Christine Deschamps, director, Library of the University Paris V, France, was elected as the new president of IFLA. Nancy John from the University of Illinois, Chicago, was elected to the IFLA Executive Board. Ed Valauskas was reelected to the professional board.
Several important resolutions were passed by the IFLA Council. Two new committees were established, one on Freedom of Access to Information and Freedom of Expression, and the other on Copyright and Intellectual Freedom. Other resolutions passed also addressed censorship and freedom of information issues in several countries.

\section{University and General Research Libraries Section}

The IFLA University and General Research Libraries Section (460 members), on which I serve as one of four U.S. representatives, has continued to work on its major topics:

- Performance Measurement. Much interest continues to be focused on this topic, and the Discussion Group sponsored a wellattended session.

- Cost Analysis of Library Operations. Roswitha Poll from the University of Muenster, Germany, is chairing a task force working on identifying international guidelines to develop cost data within academic libraries.

The section sponsored a session and a workshop on "Financing and Budgeting in a Time of Change," both of which were very successful and generated much interest. Another session sponsored by the section addressed issues of ownership and availability of electronic information.

- Management of Academic Libraries. The section continues to sponsor discussions and workshops to address management issues on an international basis.

For the next four years the section set the following scope and goals:

- Promote development and good management of university and research libraries:

- Performance indicators

- Cost guidelines

(IFLA cont. on page 712) 


\section{LOOKING FOR A \\ CAtaloging Partner?}

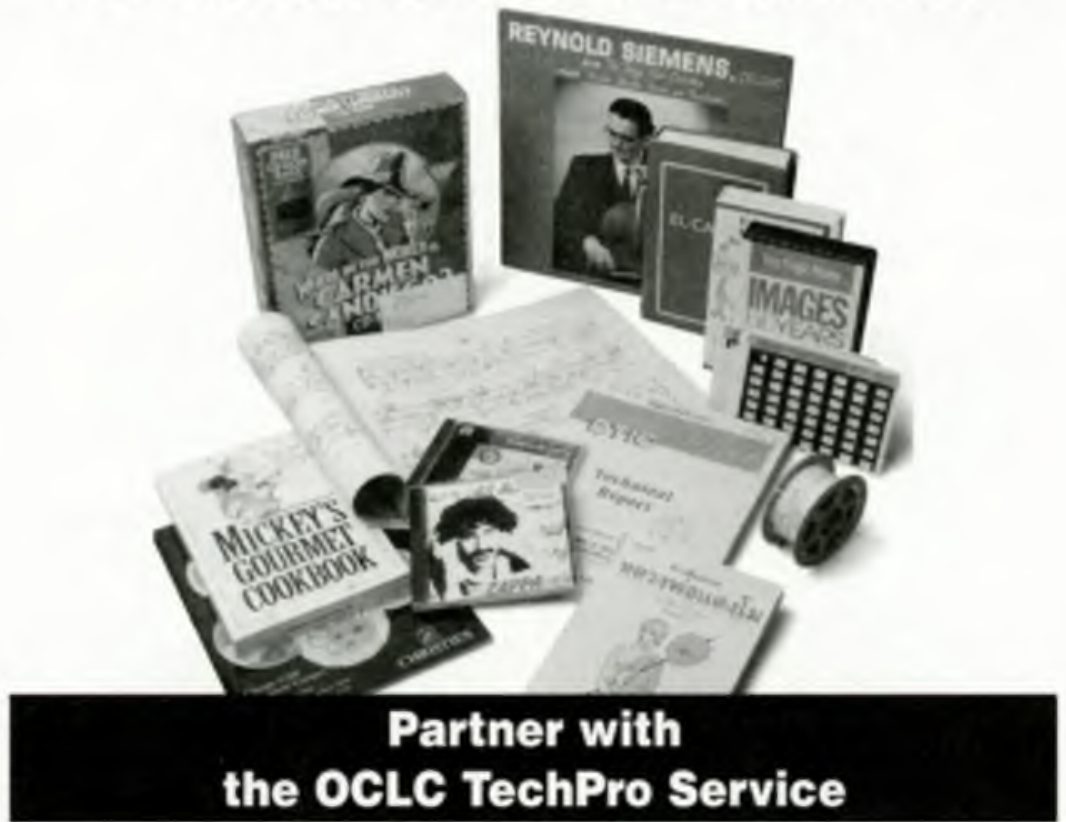

Since 1985, the OCLC TechPro service has helped hundreds of libraries eliminate their cataloging backlogs and keep pace with ongoing cataloging, giving patrons prompt access to materials.

TechPro offers:

- Customized cataloging and physical processing to match your exact specifications

- Cataloging of materials in all bibliographic formats and in many languages

- Quality cataloging at prices that can reduce your overall cataloging costs

Here is another option to consider: the new TechPro Basic Price Option. This streamlined cataloging service is designed for libraries that need help getting recently published books and serials cataloged but without complex editing or having extensive local information added to records. If your project is straightforward, this simplified approach to contract cataloging may be just what you need.

Looking for a partner to keep your cataloging up-to-date? Contact the OCLC TechPro service today. 
the patron that it can be difficult and frustrating and that it takes practice to develop compelence. In classes we make it a point to tell students that they aren't expected to be experts on the basis of one 50-minute session. We librarians are experts and we are here to help.

Library instruction is designed to introduce concepts and skills. If they aren't practiced, they aren't mastered. Nobody expects a freshman engineering student to build a bridge after his or her first class. Neither do we expect students to become expun researchers without effort.

Fee-based research service performed by experts is quite common and effective in corporate environments, law firms, and other special libraries. In the academic world, undergracluates are supposed to learn the basic skills of information literacy. Without those skills, they will be unable to evaluate the quality and valiclity of the information they encounter. This premise is applied in many other areas of education as well. Nearly everybody uses a calculator to perform basic mathematical operations; but students are still talught to do addition and subtraction by hand. You won't understand the results if you clon't understand the underlying concepts. That is why librarians are supposed to teach students how to access and analyze information.

\section{(IFlA cont. from page 709)}

- Library's integration into core function of university

- Support IFLA's focus on the electronic environment:

- Copyright laws

- Electronic formats.

\section{Elsewhere at IFLA}

IFLA's Roundtable on User Education sponsored another successful program during its fourth IFLA conference, this one entitled "Library Gateways and User Education."

Special keynote speakers such as Ms. Sibanyoni, South African Woman of the Year for 1997, combined with special cultural events in libraries and Copenhagen's cultural institutions, made this meeting most enjoyable and educational. sight-seeing within the city and quick boat trips to Sweden provided additional benefits for all conference participants. Of course the Danish drink and food, including the famous smorgashord, were most delicious. Particularly striking was the fact that Copenhagen is such a sate yet very open city. It really does feel like living in a "butter hole," as several natives referred to their city and country.

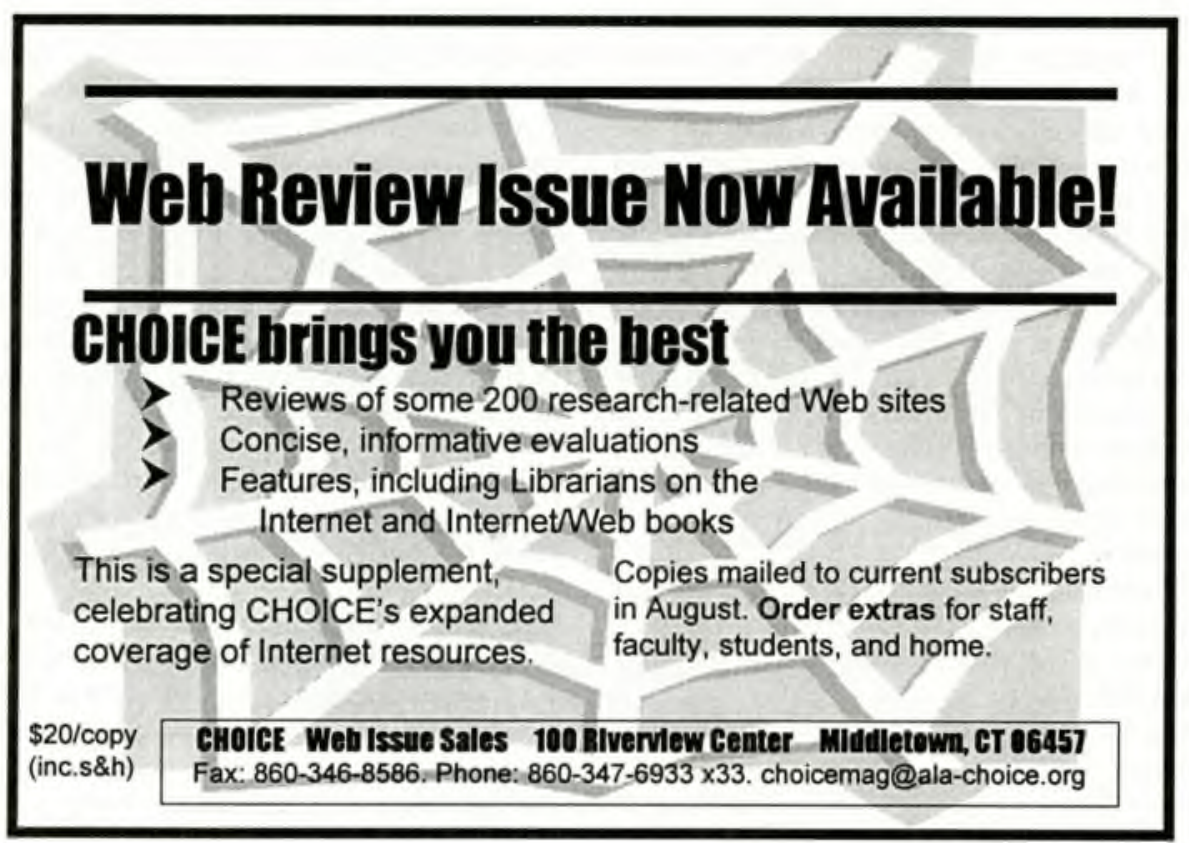

